\title{
International Collaboration in the Field of Educational Research: A Delphi Study
}

\author{
Melissa Bond ${ }^{1} \oplus$, Victoria I. Marín ${ }^{2} \odot$ and Svenja Bedenlier ${ }^{3}$ \\ ${ }^{1}$ Institute of Education, University College London, United Kingdom \\ ${ }^{2}$ Department of Pedagogy, Universitat de Lleida, Spain \\ ${ }^{3}$ Department of Education, Friedrich-Alexander-Universität Erlangen-Nürnberg, Germany
}

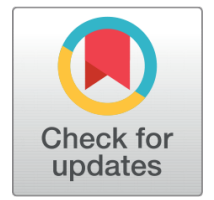

Received 2020-06-27

Revised 2020-08-03

Accepted 2020-10-26

Published 2021-07-15

\section{Corresponding Author}

Victoria I. Marín,

victoria.marin@udl.cat

Faculty of Education, Psychology and Social Work - Universitat de Lleida, Campus de Cap Pont, Avda. Estudi General 4, 25001 Lleida, Catalonia, Spain

DOI https://doi.org/10.7821/ naer.2021.7.614

Pages: 190-213

Distributed under

Creative Commons CC BY 4.0

Copyright: (C) The Author(s)

\section{OPEN ACCESS}

\section{ABSTRACT}

(International) research collaboration (IRC) is considered one of the most important aspects of academic careers and, although it is often linked to co-authorship, investigations of academic perceptions and practices are rare. Reflections on factors affecting IRC, as well as effective technology for use in IRC are also now particularly vital, due to the outbreak of COVID-19. The aim of this three-round Delphi study, conducted prior to the pandemic, was to explore why and how academics conduct IRC in the field of Education. The results indicate that the benefits of IRC are more relevant than the barriers, and that networking with and learning from others are two of the most important reasons for conducting IRC. Four stages of IRC were identified, alongside a range of influencing factors, which could inform future project management training. Suggestions for institutional IRC policy are provided, as well as considerations for early career researchers.

\section{Keywords EDUCATIONAL RESEARCH, DELPHI METHOD, INTERNATIONAL RESEARCH COLLABORATION, EDUCATIONAL POLICY}

\section{INTRODUCTION}

International research collaboration (IRC) has become "one of the hottest topics in recent years" (Chen et al., 2019, p. 149), with a growing number of studies in the field of bibliometrics and scientometrics in particular, and increases in international co-authorship found across a range of contexts (e.g., Abramo et al., 2019; Gazni et al., 2012). It has become even more important in light of the 2020 Coronavirus pandemic, with the extent to which countries have been affected by COVID-19, found to increase the likelihood of international collaboration (Lee \& Haupt, 2020b), as well as a greater increase of internationally co-authored science and engineering research on COVID-19, than those arising from IRC in the past (Lee \& Haupt, 2020a). Despite this, the very nature and definition of (international) research collaboration, alongside its measurement, has been contested (e.g., Bardakc1 et al., 2018; Bu et al., 2018; Macfarlane, 2017). Whilst co-authorship is a popular and accepted measure of research collaboration, not all research collaborations result 
in co-authored publications (Chen et al., 2019; Kumar \& Ratnavelu, 2016); rather, further data needs to be considered alongside co-authorship (Hall et al., 2018; Kahn, 2018), and in particular, studies are required that explore researcher perceptions and practices (DeHart, 2017; Henriksen, 2018; Wöhlert, 2020; Yemini, 2019).

This article seeks to add to the body of knowledge on IRC, by focusing on researcher perceptions based on self-reported practice in the field of educational research, prior to the COVID-19 pandemic. Whilst co-authored Social Science publications have increased (Gazni et al., 2012; Henriksen, 2018), including in the field of Education and Educational Research (Bond, Zawacki-Richter, \& Nichols, 2019; Henriksen, 2016), the number of publications arising from international collaborations within this field has not increased at quite the same pace (Bond \& Buntins, 2018; Kwiek, 2018, 2019b). Bibliometric data has been shown, however, to underestimate collaboration levels (Iglič, Doreian, Kronegger, \& Ferligoj, 2017), due to hidden international collaborations not expressed through co-authorship (Khor \& Yu, 2016). In response to calls for further research on technology use by researchers for collaboration (Hall et al., 2018; Leahey, 2016), as well as on the costs and challenges of IRC (Chen et al., 2019), this article presents the results of a three-round Delphi study, conducted between October 2018 to January 2019, exploring researcher understanding of the reasons, benefits and barriers of collaborating internationally in educational research; a field in need of further exploration in regards to IRC (Wöhlert, 2020). It will particularly focus on the impact of digitalisation, given the issues previously identified when using technology to facilitate international collaboration (Bukvova, 2010), as well as the importance of technology for research and collaboration during the COVID-19 pandemic, and will then provide recommendations, to help guide institutions to facilitate IRC.

\subsection{Literature Review}

Research collaborations, both within and between institutions, are becoming increasingly vital in light of progressively complex societal problems, and the intensely difficult situation arising from the outbreak of COVID-19. Despite collaboration being described as a "very fuzzy” (Katz \& Martin, 1997, p. 8) concept 20 years ago, it is still considered 'elusive' (Bardakc1 et al., 2018), 'complex' (Bu et al., 2018), and 'slippery' (Macfarlane, 2017). At the beginning of this study, the authors therefore defined collaboration as the "mutually beneficial relationship between two or more parties who work together toward common goals by sharing knowledge, learning, responsibility, authority and accountability for achieving results" (Crisplin \& Larson, 1994, p. 5 as cited in Macfarlane, 2017, p. 473).

\subsubsection{Growth of Co-Authorship and IRC}

Co-authorship has increased within a variety of disciplines, including Chemistry (Kato \& Ando, 2013), Economics (Kuld \& O’Hagan, 2018), Physiotherapy (Remedios \& Gummesson, 2018), and Educational Technology (Bond et al., 2019), as well as across disciplines (e.g. Italy, see Abramo et al., 2019) and regions (e.g. Europe, see Kwiek, 2020a; 2020b). How- 
ever, there is much disparity in the level of co-authorship between disciplines, with a study of 14 million publications indexed in the Web of Science (Gazni et al., 2012) revealing that, whilst $89 \%$ of Life Sciences publications were co-authored between 2000 and 2009, only $36 \%$ of Social Sciences publications were co-authored during the same period, likely owing to the cost and experimental nature of science (Abramo et al., 2019; Kumar, 2018). Due to this large disparity in co-authorship across disciplines, it has therefore been suggested that it is more appropriate to study IRC within individual research fields (Guo, Zhang, \& Guo, 2016; Ponomariov \& Boardman, 2016), hence the focus of this study on the field of Education.

In a study of 21 million publications across all disciplines (Waltman, Tijssen, \& van Eck, 2011), the average collaboration distance per publication had increased from $334 \mathrm{~km}$ in 1980 to $1553 \mathrm{~km}$ in 2009 . However, the increases in IRC have been smaller than the general increase in co-authorship (Bond \& Buntins, 2018; Kwiek, 2018), despite the number of co-authored articles increasing from 30\% to almost 70\% between 1980-2013 (Henriksen, 2016). There were also early signs of growth in the field of Education, with a study of 92,820 articles revealing that IRC had grown from $14.1 \%$ in 2002 to $21.7 \%$ in 2013 (Aman \& Botte, 2017). However, the share of IRC varied greatly from country to country, with Switzerland having the highest proportion of internationally co-authored publications in Europe (48.7\%), compared to Turkey (11.1\%). A study of 11,046 publications in the field of Educational Technology between 2000-2012 (Guo et al., 2016) revealed an overall IRC rate of $2.05 \%$, with $95 \%$ authored from domestic only collaborations, and $78.82 \%$ of publications authored within a single institution.

Another method of analysing international collaboration and communication is through citation analysis. A study by Marín and Zawacki-Richter (2019) investigated the relationships between Spanish and English-speaking educational technology research communities, through a social network analysis of research published in eight open access journals (3,407 articles). The study found that, whilst Spanish authors cite papers in English language journals, English language studies do not cite studies from Spanish journals, even when published in English. Marín and Zawacki-Richter (2019) also found that the Spanish research community seems to be more tightly connected, interacting and collaborating amongst themselves, particularly through conferences and social networks.

There has also been some concern that, despite a noted rise in internationally coauthored research in some disciplines during the COVID-19 pandemic (Lee \& Haupt, 2020a), new IRCs are not necessarily being formed, including within the field of Education (Hook \& Porter, 2020), with developing world collaborations the hardest hit (Buitendijk et al., 2020; Fry, Cai, Zhang, \& Wagner, 2020). Given this disparity, and to gain a more nuanced understanding of IRC in the field of Education, further probing into the factors affecting IRC is needed.

\subsubsection{Factors Affecting IRC}

Whilst IRC and international communication appears to be continuing on during the COVID-19 pandemic, despite differences in location and time zone (Bogle, 2020), scien- 
tific nationalism and international strain have impacted on the level and depth of IRC that has developed (Lee \& Haupt, 2020b). Whilst this has been centred more on funding and authorship in regard to finding a vaccine (Stevis \& Jakes, 2020), this has also affected policies and overarching funding sources, which impact on IRC in all fields (Baker, 2020; Gorska, Korzynski, Mazurek, \& Pucciarelli, 2020). So profound an impact has the pandemic had on IRC, it has prompted a major call by the National Science Foundation for rapid research and grant proposals, to be taken up in 2021 (National Science Foundation, 2020) investigating the nature and construct of IRC during this difficult time.

Socio-cognitive and emotional factors relate to the micro level and include trust and social presence, with initial face-to-face meetings found to enable more complex and intense interactions (Ku, Gil-Garcia, \& Zhang, 2016; Wöhlert, 2020). Researchers who have collaborated before are also more likely to collaborate together again (Fernández, Ferrándiz, \& León, 2016), with one educational researcher in Yemini’s (2019) study likening IRC to cliques in high school and describing it "like Beverley Hills 90210" (p. 9). In a systematic review of 46 transnational collaborations, published between 1994-2016, Caniglia et al. (2017) identified two major challenges; institutional policy challenges, at both the national and international levels, and intercultural challenges, such as cultural habits and language barriers (Wöhlert, 2020), as well as learning habits. Scientists who are more established in their career, tend to decrease their domestic publications, in favour of international collaboration (Abramo et al., 2019), which are also more likely to attract increased citations (Adams, 2013; Aman \& Botte, 2017) and collaborations (Gorska et al., 2020), therefore career stage is an important consideration.

Aside from these factors, IRC can result in a number of additional challenges. These include work overload (Bardakc1 et al., 2018), such as increased administration (Katz \& Martin, 1997), confusion over authorship order and attribution (Bozeman, Gaughan, Youtie, Slade, \& Rimes, 2016; Bukvova, 2010; Yemini, 2019), and potentially less productivity, particularly as a result of navigating differing work cultures (Abramo et al., 2019; Yemini, 2019).

\subsubsection{Benefits of IRC}

Despite the challenges that IRC can present, there are many benefits, including a wider network (Katz \& Martin, 1997; Yemini, 2019) and an increased likelihood of collaborating with multiple authors in the future (Aksnes, Frølich, \& Slipersæeter, 2008; Kumar \& Ratnavelu, 2016). Articles involving international collaboration have been found to receive increased citations (Abramo et al., 2019; Adams, 2013; Fu et al., 2012), although an investigation into twenty years of Chemistry research did find that researchers with a mixture of domestic and international papers outperformed those with only international papers (Kato \& Ando, 2013). Despite this, it has been found that the number of researchers collaborating domestically in Poland is higher than the percentage of those who only collaborate domestically (Kwiek, 2020a), thus indicating that the performance of researchers with only internationally authored papers may still be better off. 
IRC enables researchers to share resources and costs between institutions (Abramo et al., 2019; Bogle, 2020; Niederkrotenthaler et al., 2020), as well as knowledge and skills (Katz \& Martin, 1997; Melin, 2000), which can therefore lead to increased productivity (Bote, Olmeda-Gómez, \& de Moya-Anegón, 2013; Bothwell, 2019; Hall et al., 2018) and improved research quality (Kumar \& Ratnavelu, 2016; Mali, Pustovrh, Cugmas, \& Ferligoj, 2018). Collaborating with international colleagues has been shown to improve university quality indices (Aldieri, Kotsemir, \& Vinci, 2018; Times Higher Education, 2019), which can also increase a researcher's chances of receiving both internal and external funding (Zhou \& Tian, 2014).

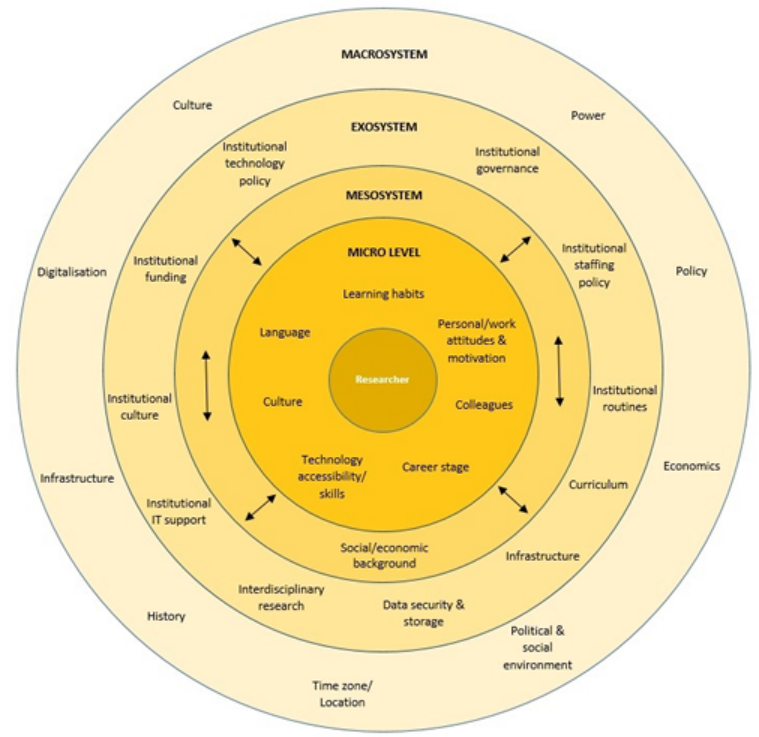

Figure 1 Factors affecting IRC, structure adapted from Bond and Bedenlier (2019, p. 4)

IRC has been found to be particularly crucial since the outbreak of COVID-19; not only has IRC been critical within scientific and medical fields (see e.g. John et al., 2020), but the importance of inter-disciplinary teams is being increasingly recognised for helping work towards combating the effects of the disease (Queen's University Belfast, 2020).

\subsubsection{Technology Used in IRC}

Whilst the self-ethnography by Hoffman et al. (2014) astutely points out that "there is not a magic solution that different people (in different generations, countries, cultures, disciplines, institutional settings, career stages) can adhere to, in using different combinations of ICT tools to communicate" (p. 490), there are some tools that have been found to be more effective in IRC. In a Kenyan study (Muriithi, Horner, Pemberton, \& Wao, 2018), phone, email and face-to-face meetings were the most common, with poor internet connectivity and technical support prohibitive factors. Ynalvez and Shrum (2011) found that diversity of email use was more strongly associated with increased network size, and email intensity predicted involvement in IRC in a South African study (Sooryamoorthy \& Shrum, 2007), 
although email use alone was found insufficient in a French and English collaboration (Jonsen et al., 2013). Using emails and other asynchronous technology can provide researchers with take-up time, to absorb and re-read information, which is especially useful in multilanguage research teams (Wöhlert, 2020). However, Berthoud and Gliddon (2018) explored the use of wikis in collaborative projects and found that, whilst it did aide collaboration, ongoing technical problems hindered its use, with the requirement for sufficient training prior to its use a key need identified.

In a study of 95 Turkish academics from 34 institutions, Bardakc1 et al. (2018) found that most researchers use asynchronous social networks, such as Academia.edu, Google Scholar and ResearchGate, but that very few use them for communication or for collaborative knowledge building, with some researchers in Hoffman et al. (2014) study finding ResearchGate overwhelming for collaboration, despite its benefits for IRC, particularly during the initial phase of building a research team (Gorska et al., 2020). A case study of academic social network site use in Japan (Mason, 2020) also found that usage was rank dependent, with the likelihood decreasing as researchers moved to more senior positions. In a qualitative meta-synthesis of 68 studies investigating scientific collaboration using social networking sites (SNS) (Salinas \& Marín, 2019), the authors explored the role of academic and general SNS for academic collaboration, including IRC. The findings showed that only one study mentioned IRC as one of the benefits of SNS and that most of the studies were more focused on how to build reputation and alternative ranking systems, rather than the individual and collective practices and new ways of academic communication in research (Salinas \& Marín, 2019, p. 108). Technology use in IRC had, however, also been found to play only a minor role in pre-COVID-19 times, with some research groups preferring to discuss issues in face-to-face settings (Ku et al., 2016). There are also still considerable challenges when using ICT in IRC, such as researcher and institution levels of technical readiness, the change to online environments where trust building might be difficult, security, and group coordination (Bukvova, 2010; Stokols, Misra, Moser, Hall, \& Taylor, 2008; Wöhlert, 2020). The ability of researchers and conferences to switch to online ways of collaborating and working as a result of the COVID-19 pandemic, has sparked a "renewed recognition of the value of distance learning" (Bogle, 2020) and the use of technology for IRC, such as video conferencing, "becoming the norm...in spite of time zone differences".

Therefore, when this research study was first conceptualised in 2018, further investigation of how technology is used in IRC (effectively) was needed (Leahey, 2016), and this is perhaps arguably even more vital now, given current working conditions in most countries around the world today.

\section{MATERIAL AND METHODS}

Against this background, the main research question for this study was: How does international academic research collaboration occur in the field of Educational Research? The following sub-questions were also posed:

1. How do education researchers understand 'international research collaboration'? 
2. What first and second-order reasons do educational researchers have to conduct international research collaboration?

3. What stages do educational researchers consider in the process of international research collaboration and what kinds of technology are implemented in each of them?

4. What do educational researchers consider as the first and second-order benefits and barriers of international research collaboration?

\subsection{Delphi Method and Survey Instrument}

In order to elicit educational researchers' perspectives and experiences of IRC, we conducted a Delphi study, following the method of Fake (2018). Linstone and Turoff (2002) describe it as "a method for structuring a group communication process so that the process is effective in allowing a group of individuals, as a whole, to deal with a complex problem" (p. 3). Hsu and Sandford (2007) describe the main features of this technique as being an iterative one, including several rounds of questioning experts on a specific topic -whilst keeping their identity from each other to avoid bias, through which consensus on the topic or question is eventually reached. Experts for participation are chosen based on their intimate and extended knowledge of the topic in question. Characteristics of the Delphi technique are anonymity, controlled feedback from the interaction, an assessment of the group view, an opportunity for individuals to revise their opinions, and the statistical group response (Okoli \& Pawlowski, 2004; Yousuf, 2007).

In this Delphi study, three rounds of two weeks each were conducted. In Round One, an online survey was sent to participants via Lime Survey, which contained three sections following the agreement to participate: demographic information, IRC experience, and Delphi questions, which were directly related to the study research questions (see Appendix B). The results of Round One were then used in the second round, to help gain consensus on the definition of IRC and the other questions, with some combined due to their similarity. The objective of the second round was, therefore, that experts positioned themselves regarding the previously brainstormed items. A 10-point Likert-scale was used to assess this consensus, with 1 being absolutely disagree, and 10 completely agree. Each item also had an open text box to add additional comments, if needed.

The main aim of Round Three was to reach consensus about the relevance or lack of importance of the different items presented in Round Two. This Round Three survey also included the anonymous mean and standard deviation scores for each of the items (without consensus) of the Delphi questions, so that participants could reflect upon their own responses.

\subsection{Panel Description}

The selection of the experts in this study was based on their involvement as a member of the editorial board of four of the top Education \& Educational Research journals (Review of Educational Research, Computers \& Education, Internet and Higher Education, and Educational Research Review), according to impact factor in the Social Sciences Citation Index 
2017. We posited that these academics were senior experts in educational research and, due to the prestige and international reach of the journals (Tight, 2018), they were likely to have expertise in IRC. To make sure that this latter was the case, we included a question regarding IRC within the second section of the questionnaire to consider the general expert competency in IRC, which allowed us to continue with experts that actually had IRC experience. We also reasoned that editorial boards of international journals would include researchers from a variety of institutions and countries, which could help reduce the "potential bias associated within institutional cultures and structures" (Muriithi et al., 2018, p. 90).

To further validate the journals selected, the authors conducted an analysis of all articles published from 2015-2019 $(n=1353)$. Of these, $920(68.0 \%)$ were domestic only publications, that is written by authors from institutions within the same country, 277 (20.5\%) were international (articles that included authors from at least two different countries), and a mere 156 articles (11.5\%) were solo authored. The Internet and Higher Education had the highest percentage of IRC articles $(26.2 \%, n=38)$, with the Review of Educational Research the lowest $(14.4 \%, n=19)$. The rate of IRC is very similar to previous studies that have been conducted in the field of education research (e.g., Aman \& Botte, 2017), and therefore the choice of journals was deemed appropriate.

Of the 183 experts who were invited to participate via email in October 2018, 23 voluntarily agreed to participated in the first round of the study. Whilst the number of participants dropped to 17 in the second round and 14 in the third round, panels of 10-18 experts are recommended in Delphi studies (Okoli \& Pawlowski, 2004), as "Delphi group size depends on group dynamics rather than statistical power” (O’Neill et al., 2011, p. 941). We could venture that most of the invited experts in the first place did not have much experience in international collaboration, being closer to the low percentage of international publications observed in the journals in the field, and therefore, did not take part in the study.

Background information of the experts participating in the study was collected in Round One (see Table 1). The average age of the experts was 56.5 years (min. 28 and max. 96) and the mean of years of experience after completing a $\mathrm{PhD}$ was 19.3. The language of communication for IRC was English for all participants, although two experts also mentioned Dutch, and Italian, Japanese and German were also each mentioned once. Most of the participants were born in the country where they currently work (see Table 2), although some of them have previously changed their country of affiliation $(n=10)$. Interestingly enough, most of the affiliated institutions do not have an IRC policy $(60.9 \%)$.

Concerning international co-authors, $43.5 \%(n=10)$ of the experts have partners in five or more different countries, $34.8 \%(n=8)$ between 2 and 4 countries, $17.4 \%(n=4)$ in only one country, and $4.3 \%(n=1)$ have no international partners. 
Table 1 Background data of panel experts

\section{Background Information}

(1) Gender

(2) Position

(3) PhD holder

(4) Articles co-authored

(5) Institution of affiliation has policy for international collaboration

(6) Years of research experience after $\mathrm{PhD}$

\begin{tabular}{|c|c|c|}
\hline Options & $f$ & $\%$ \\
\hline Female & 10 & $43.48 \%$ \\
\hline Male & 12 & $52.17 \%$ \\
\hline Prefer not to say & 1 & $4.35 \%$ \\
\hline Professor & 12 & $52.17 \%$ \\
\hline Associate Professor & 3 & $13.04 \%$ \\
\hline Professor Emeritus & 1 & $4.35 \%$ \\
\hline Research Fellow & 4 & $17.39 \%$ \\
\hline Head of School/Research Institute & 2 & $8.70 \%$ \\
\hline Associate Provost & 1 & $4.35 \%$ \\
\hline Yes & 22 & $95.65 \%$ \\
\hline No & 1 & $4.35 \%$ \\
\hline $0-5$ & 10 & $43.48 \%$ \\
\hline $5-10$ & 5 & $21.74 \%$ \\
\hline $10-15$ & 1 & $4.35 \%$ \\
\hline More than 15 & 7 & $30.43 \%$ \\
\hline No & 14 & $60.87 \%$ \\
\hline Expected/Encouraged/Recommended & 6 & $26.09 \%$ \\
\hline Yes & 2 & $8.70 \%$ \\
\hline Do not know & 1 & $4.35 \%$ \\
\hline $0-5$ & 3 & $13.04 \%$ \\
\hline $6-10$ & 1 & $4.35 \%$ \\
\hline $11-15$ & 6 & $26.09 \%$ \\
\hline $16-20$ & 6 & $26.09 \%$ \\
\hline $21-25$ & 0 & $0.00 \%$ \\
\hline $26-30$ & 1 & $4.35 \%$ \\
\hline $35-40$ & 3 & $13.04 \%$ \\
\hline More than 40 & 2 & $8.70 \%$ \\
\hline Did not respond & 1 & $4.35 \%$ \\
\hline
\end{tabular}

Table 2 Experts' continent of birth and current affiliation

Continent of birth Continent of affiliation

\section{Continent}

North America (US)

Europe

$f \quad \%$

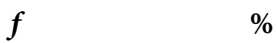

$626,09 \%$

$12 \quad 52,17 \%$

Africa (South Africa)

2

Australia/Oceania

Asia

N/A

TOTAL

1

1

1

23

\begin{tabular}{lll}
$\%$ & $f$ & $\%$ \\
\hline $26,09 \%$ & 9 & $39.13 \%$ \\
$52,17 \%$ & 9 & $39.13 \%$ \\
$8,70 \%$ & 2 & $8.70 \%$ \\
$4,35 \%$ & 3 & $13.04 \%$ \\
$4,35 \%$ & 0 & $0.00 \%$ \\
$4,35 \%$ & 0 & $0.00 \%$ \\
$100,00 \%$ & 23 & $100.00 \%$
\end{tabular}




\section{RESULTS}

\subsection{Definition of IRC}

The definition of IRC, resulting from a synthesis of answers from the first round, reached broad agreement consensus $(\mathrm{M}=8.94, \mathrm{SD}=0.966)$ :

International research collaboration involves researchers from different countries, cooperating on small to large-scale funded or non-funded projects, which can involve discussing ideas, presenting at conferences, preparing grant proposals, conducting comparative research, and writing joint scholarly publications between team members.

However, some interesting remarks were made, such as that the definition was very broad or whether including "small to large scale" or "funded and non-funded" was necessary. Other experts commented that IRC is not necessarily comparative, and alternatively suggested, "conducting joint research or conducting research". Another remark was directed at the number of elements that should be considered to be IRC (several of them, at least two). An adapted version of the definition was therefore included in the second round, and again reached broad agreement consensus $(\mathrm{M}=8.86, \mathrm{ST}=0.663)$ :

International research collaboration involves researchers from different countries, cooperating on research projects, which involve two or more of these activities: discussing ideas, presenting at conferences, preparing grant proposals, conducting joint research, and/or writing joint scholarly publications between team members.

Some experts highlighted further aspects to consider, e.g. who is responsible for joint research, the relation between projects and funding and the informal character of research collaborations, as well as the intentionality of IRC.

\subsection{Reasons for Conducting IRC}

The experts were asked in Round One what their reasons have been/are for undertaking IRC and the answers were aggregated into fourteen different responses (see Table 3). The reasons that reached strong agreement consensus in Round One, and which are therefore considered first-order reasons for conducting IRC, were:

- having shared interests

- to learn from others

- sharing and exploring different ideas and multiple perspectives

- challenging own ideas

Other statements remained relatively controversial, potentially due to referring to one's personal experiences, perceptions and context. Participants were then asked to rank them in Rounds Two and Three, in order to see if further consensus could be reached. Although 
there were still items where the consensus was not clear, due to the high standard deviation, we can consider that networking with others, admiration of the work of international colleagues, more interesting research questions and "international collaboration is fun" as second-order reasons to conduct IRC. Reasons such as flexible choice of collaborators, enhanced reputation and prestige for the own institution and career, access to data, acquisition of funding and international travel are considered as not highly influential or relevant. Some of the experts' comments that bring light to those choices and contribute to the discussion can be observed in Appendix A.

Table 3 Reasons for conducting IRC

\begin{tabular}{|c|c|c|c|c|}
\hline \multirow[b]{2}{*}{ Item } & \multicolumn{2}{|c|}{ Round Two } & \multicolumn{2}{|c|}{ Round Three } \\
\hline & $\mathbf{M}$ & SD & M & SD \\
\hline Networking with others & 7,71 & 1,53 & 7,29 & 1,72 \\
\hline Flexible choice of collaborators & 6,59 & 2,69 & 6,86 & 1,74 \\
\hline Admiration of the work of international colleagues & 7,71 & 2,02 & 7,14 & 2,17 \\
\hline Enhanced reputation and prestige for my organisation/institution & 5,47 & 2,47 & 6,29 & 2,23 \\
\hline Enhanced reputation and prestige for one's own career & 6,35 & 2,95 & 6,36 & 2,13 \\
\hline Access to data & 6,29 & 2,66 & 5,93 & 1,97 \\
\hline Acquisition of funding & 6,59 & 2,91 & 6,21 & 1,92 \\
\hline International travel & 5,47 & 3,35 & 4,71 & 2,33 \\
\hline More interesting research questions & 7,29 & 2,46 & 7,86 & 1,46 \\
\hline "International collaboration is fun" & 7,24 & 2,75 & 7,00 & 1,92 \\
\hline
\end{tabular}

\subsection{Stages of IRC}

Consensus was largely achieved in Round One regarding the appropriateness of the stages of international collaboration $(\mathrm{M}=8.06, \mathrm{SD}=1.519)$, which were:

1. Initiation: Meeting face-to-face or online, exchanging first ideas and discussing interests

2. Design: Refining the research problem, developing a procedure for conducting the research, distributing tasks

3. Execution: Collecting and analysing data, possibly in different countries, and writing up the results

4. Dissemination: Submitting and revising the manuscript, joint publications.

However, one expert pointed out as missing steps: data analysis, articulating findings and thinking about implications, which could also be understood as being an integral part of stage 3 .

\subsection{Technology Use in IRC}

Experts were also asked in Round One which technological solutions for IRC are offered by their institution and whether they are used, with 19 participants (83\%) reflecting upon 
their use of technology (see Table 4). One of the experts commented that "communication cuts across [all] stages" of IRC, with email being the predominant form of communication mentioned, followed by videoconferencing, with Zoom and Skype the most frequently mentioned, although Adobe Connect and WhatsApp were also used.

Most of the panel members reported the provision of institutional technology services, such as cloud storage or video conference applications, with one expert commenting that "video provides a shared non-linguistic tool". However, difficulties of working with those services were also mentioned; the services being sometimes considered rudimentary, unstable or not reliable enough. Despite this, due to the new GDPR (General Data Protection Regulation), researchers residing in Europe are required to use institution-specific tools, instead of external services. Use of third-party services (e.g., Dropbox, Transfer, Google Docs) was also indicated, sometimes with personal accounts used instead of institutional ones. One expert commented that they actually "often have more contact [through email and video conferencing] than with colleagues in [their] building". Face-to-face meetings were also quite popular $(n=10,43 \%)$, especially at the beginning and towards the end of collaboration for developing research proposals, along with collaborative documents and cloud storage.

Table 4 Technology used in IRC $(n=19)$

\begin{tabular}{lll} 
Technology & $\boldsymbol{f}$ & \% \\
\hline Email & 15 & $78.95 \%$ \\
Video conferencing (e.g. Skype) & 13 & $68.42 \%$ \\
Face-to-face & 10 & $52.63 \%$ \\
Collaborative writing (e.g. Google Docs) & 8 & $42.11 \%$ \\
Shared folders (e.g. Google Drive, Dropbox) & 6 & $31.58 \%$ \\
Slack & 1 & $5.26 \%$ \\
Concept Mapping (Concept System Global Max) & 1 & $5.26 \%$ \\
Word processing (MS Word) & 1 & $5.26 \%$ \\
Social media (Facebook, Twitter, LinkedIn) & 1 & $5.26 \%$ \\
\hline
\end{tabular}

\subsection{Benefits of Conducting IRC}

The experts reached high positive consensus in Round One with regards to the (first-order) benefits of conducting IRC:

1. learning from and connecting with others $(\mathrm{M}=9.06, \mathrm{SD}=0.966)$

2. broadened research experiences $(M=8.76, S D=1.147)$, and

3. diversity of perspectives $(\mathrm{M}=8.18, \mathrm{SD}=1.185)$

The consensus was even clearer in Round Two (see Table 5). The decrease in the standard deviations of those items in Round Three enabled us to identify broader research impact and global accessibility of knowledge and experts as second-order benefits when conducting IRC. On the other hand, increased work output was a rather dismissed benefit of this type of collaboration. One expert remarked that global accessibility of knowledge and experts is 
"a side-effect of collaboration, not a benefit". Another interesting comment was about the benefit increased work output: "This is a two-edged sword. Yes, there are more outputs but in my context any output produced by more than one author counts less".

Table 5 Benefits of conducting IRC

\begin{tabular}{|c|c|c|c|c|}
\hline \multirow[b]{2}{*}{ Items } & \multicolumn{2}{|c|}{ Round Two } & \multicolumn{2}{|c|}{ Round Three } \\
\hline & $\mathbf{M}$ & SD & $\mathbf{M}$ & SD \\
\hline Broader research impact & 7,94 & 1,6 & 7,79 & 1,36 \\
\hline Global accessibility of knowledge and experts & 8,06 & 1,74 & 7,57 & 1,39 \\
\hline $\begin{array}{l}\text { Increased work output (e.g. more publications and citations, quicker publication, sharing } \\
\text { workload) }\end{array}$ & 6,65 & 2,49 & 6,5 & 1,28 \\
\hline
\end{tabular}

\subsection{Barriers to Conducting IRC}

A tentative conclusion that can be drawn about the barriers to conducting IRC from Round One, is that the identified aspects are overall not necessarily impediments to collaboration. Given the high standard deviations, this section was revisited in Round Three. An expert raised the issue of different ethical requirements in some countries, which can make researchers worry about the protocols that may not be followed by international partners, and another practical remark was made on the difficulties of executing payments, due to the lack of invoices that are given in some countries. In our view, these comments confirm the barrier of cultural differences, including academic culture and customs, which vary between countries.

Similar to the benefits of IRC, the means and standard deviations for barriers to IRC in Rounds Two and Three were varied (see Table 6). Given the high standard deviations and the low means obtained in both rounds, these educational researchers do not consider IRC to have many barriers, but rather emphasise the opportunities and good reasons to do so.

Regarding institutional constraints, one expert remarked that "funding is definitely an issue" and another drew attention to the differences between the north and south, in terms of the academic year calendars. Comments concerning language demonstrated that English is used as lingua franca and there are no major issues. However, the experts considered time management from different perspectives; for instance, in terms of IRC adding "significant pressure" on researchers, time zones as a "significant challenge" (also factor distance), and not having "time to dedicate to spend abroad". Technology is considered more as a facilitator that eases establishing contact with others; therefore, both of those barriers are discarded.

Open-text answers regarding cultural differences as a barrier brought diverse opinions to light, ranging from "not a big deal" to "should not be overlooked". The following comments also reflect those two positions:

Researchers from the Global South may experience or possibly be more sensitive to power play and the historical and continuing asymmetries in power in international research collaboration. In many cases Africa and the Global South have the data and fresh questions, the Global North has the funding and perceived/as- 
Table 6 Barriers to IRC

\begin{tabular}{|c|c|c|c|c|}
\hline \multirow[b]{2}{*}{ Items } & \multicolumn{2}{|c|}{ Round Two } & \multicolumn{2}{|c|}{ Round Three } \\
\hline & M & SD & M & SD \\
\hline Institutional constraints (e.g. culture, academic year cycles, concerns about Brexit) & 5,47 & 2,24 & 6.79 & 2.60 \\
\hline Language & 4,12 & 2,29 & 4.57 & 2.34 \\
\hline Time management & 6,94 & 2,16 & 6.43 & 1.78 \\
\hline Technology issues & 4,12 & 2,09 & 3.21 & 1.47 \\
\hline Funding & 7,00 & 2,60 & 6.57 & 1.39 \\
\hline Difficulties making contact with others & 4,00 & 2,55 & 4,00 & 1,92 \\
\hline Distance (e.g. different time zones, geographical separation) & 4,76 & 2,49 & 4.14 & 2.03 \\
\hline $\begin{array}{l}\text { Cultural differences (e.g. lack of awareness, political differences, academic cultures, } \\
\text { currency issues) }\end{array}$ & 4,65 & 2,03 & 3.86 & 2.03 \\
\hline
\end{tabular}

sumed gravitas.

Anyone collaborating has probably already met with collaborators in an international setting and so differences in culture are more differences in style.

Within this barrier, the ethics issue mentioned by an expert could have its place: "some countries do not have ethical requirements so it can be difficult working with them as they do not see the importance of informed consent, etc."

\section{DISCUSSION}

\subsection{Understanding of IRC}

The experts in this Delphi panel reached broad agreement consensus on a definition of IRC that emphasises multiple activities between researchers from different countries. This does not necessarily imply that researchers need to be physically located in dispersed countries, as IRC can occur within the same institution or country (Bukvova, 2010). For example, the authors of the current paper are from three geographically dispersed countries, with varying cultural and linguistic backgrounds, but who happened to be working at the same institution at the time of this study's conception and data collection phase. The majority of studies investigating co-authorship as a proxy of IRC would, however, miss these collaborative networks. Therefore, further weight is given to the call for future IRC research that goes beyond mere co-authorship metrics (Chen et al., 2019; Hall et al., 2018).

\subsection{Reasons, Benefits and Barriers}

This Delphi study revealed having shared interests, learning from others, sharing and exploring different ideas and multiple perspectives, and challenging own ideas as first-order drivers for conducting IRC (Katz \& Martin, 1997; Melin, 2000; Yemini, 2019), with networking, admiration, more interesting research questions, and enjoyment identified as second-order reasons (Katz \& Martin, 1997; Yemini, 2019). Remarkably, however, these reasons vary substantially from those identified in the review by Chen et al. (2019) and the literature 
review conducted for this article, with far more emphasis placed on enhancing visibility and productivity, and sharing resources (Abramo et al., 2019). Given the benefits identified that focused on IRC as a way to enhance knowledge and skills (Bukvova, 2010), rather than as a means to necessarily boost prestige, this may point to a key difference with STEM disciplines, which have been (at least initially) identified as being focused on IRC to enhance productivity and impact (Chen et al., 2019). Furthermore, given the career stages of these participants, it is likely that the results would be different, if they had been early career researchers (Mason, 2020). The results may also differ, depending on which countries participants come from (Chen et al., 2019). Therefore, further research exploring early career researcher perceptions of IRC, including institutional and support structures needed to facilitate successful IRC, from a variety of countries, is suggested.

The experts in this study were not as concerned about barriers to IRC, although funding, time management and institutional constraints ranked the highest (Katz \& Martin, 1997). This might go some way to explain why there has been noticeably less literature on the costs of IRC (Chen et al., 2019). Increased funding within the EU has resulted in an extraordinary amount of IRC and publications, with $45.75 \%$ of articles published in 2018 involving international collaboration (Kwiek, 2020b). However, in a study of 23,649 publications from 294 European researchers over 15 years (Defazio, Lockett, \& Wright, 2009), funding was found not to have enhanced productivity; rather it was the interactions among researchers that had a more positive effect. This highlights the importance of establishing trust, respectful relationships and social presence within research collaborations (Ku et al., 2016).

Participants in this study also raised issues around inequality and/or a disconnect between North/South research practices and opportunities (King, 1985). Recent research (Asare, Mitchell, \& Rose, 2020) has highlighted the importance of equitable relationships and participative research design, particularly when collaborations have been initiated by the North.

\subsection{Stages of Collaboration}

The phases of collaboration identified by the experts largely corroborate with previous literature (e.g., Sonnenwald, 2007). The fact that participants differentiated two clear stages for tasks that occur prior to any actual research being undertaken, stresses the importance of initial stage-setting and the clear division of labour (Jonsen et al., 2013), to help facilitate a smoother process, with a clear focus on working in partnership with collaborators particularly important (Asare et al., 2020). Face-to-face meetings were also flagged by participants, and in the literature (Ku et al., 2016; Wöhlert, 2020), as being vital to help build trust; trust being the "key ingredient" according to one expert in this study. However, given the difficulties of time and cost involved in travelling, further investigation into how technology could facilitate similar levels of trust in IRC is needed (Leahey, 2016), especially now when so many countries are under lockdown due to COVID-19.

Interestingly, one expert with over 35 years of research experience following their $\mathrm{PhD}$, said "[we] have been working together for so long I do not see stages", and another with 40 years of experience said that "there is not something special about international collab- 
oration other than differences in rules and larger distances". This relates to the finding in prior research (Kwiek, 2020a; Wang, Yu, Bekele, Kong, \& Xia, 2017) that more established researchers dominate IRC and have more collaborators than younger academics, and it suggests that future research may find targeting mid-career researchers more beneficial.

\subsection{Technology Use in IRC}

The most used tool by the experts to facilitate IRC in this study was email, followed by video conferencing, collaborative documents and shared cloud storage, which echoes previous research (Muriithi, Horner, \& Pemberton, 2016; Wöhlert, 2020). It is interesting to note that, whilst institutions encourage (or expect) researchers to collaborate internationally, the digital tools used by these experts for IRC are most often not provided through their institutions, or if so, they are considered insufficient compared to external services. The experts in this study resort to (free) services, whose compliance with data protection and security are somewhat questionable. This could represent an important barrier for IRC in terms of policy compliance, although participants in this study did not consider technology a barrier to IRC specifically. Also in regard to policy, an interesting finding in this study was that most participants' institutions currently do not have an IRC policy, with a striking comment by one expert, highlighting that some institutions actively continue to devalue IRC (Buckner, 2020).

Surprisingly, only one participant mentioned social media (Twitter, Facebook, LinkedIn) and no-one mentioned the use of academic SNSs in the context of their IRC. Whilst previous research has found that few academics use SNSs explicitly for collaborative knowledge building or for the active phases of IRC (Bardakc1 et al., 2018; Salinas \& Marín, 2019), a recent study (Gorska et al., 2020) found that ResearchGate (RG) is particularly useful for building a research team. Furthermore, whilst younger researchers are typically associated with being more technologically savvy, their presence on RG did not equal increased IRC; rather it was the more established, senior researchers for whom it was most beneficial. It would be interesting to explore researcher perceptions of RG and SNSs, beyond mere metrics alone, and in particular whether it is considered more as a branding tool, rather than a networking and collaborating tool.

\subsection{Recommendations}

\subsubsection{Macrosystem}

Despite prior research finding that funding did not explicitly boost IRC (Defazio et al., 2009), increased European research funding has coincided with a boom in IRC and internationally co-authored publications (Kwiek, 2020b). This suggests the importance of funding, not only for new international collaborations, but for supporting ongoing collaborations, especially in light of the amount of time it can take to establish an effective team (Wöhlert, 2020). In contrast to international funding schemes, generalised suspicion between countries can negatively influence IRC (Matthews, Yang, Lewis, Vaidyanathan, \& Gorman, 2020), this being somewhat in line with increased nationalism in various countries. Mitiga- 
tion of which is, however, intertwined with numerous factors; making it difficult as an area for specific recommendation.

Whilst the issue of geographical location has somewhat been mitigated by working conditions as a result of the COVID-19 pandemic, alongside time zones to a certain extent, the focus now at the national level should be on enhancing digitalisation capacity, not just in the field of telehealth (Horgan et al., 2020), but to support the growing number of people (and researchers) working (and learning) from home (International Telecommunication Union, 2020).

\subsubsection{Exosystem}

Whilst not recognised by all experts in this study, institutional support and funding remains vital for many researchers to be able to engage in IRC (Buckner, 2020; Kwiek, 2020b; Payumo et al., 2017), which could range from ensuring that international journal subscriptions are funded, to providing incentives for international projects (Kwiek, 2019a). This may help with raising the profile of conducting IRC, given the lack of recognition provided by some institutions, as identified in this study. Lack of recognition of IRC was also identified in a study on IRC in biology and physics (Matthews et al., 2020), so that the institutional and organisational culture could also be one area to target in order to contribute to more IRC. Equally, respondents in Matthews et al. (2020) study stated that bureaucratic processes were complex in their institutions, which leads to the suggestion of establishing workflows and administrative practice in a way that is supportive to IRC. Thus, if an institution is interested in fostering IRC, devising institutional policies for IRC and international research can be a means to this end; however, also attending to the implications that this might entail (Englander \& Uzuner-Smith, 2013).

Institutions should also be mindful of encouraging collaborations that go beyond their immediate geographical cluster, but also that establish equitable power relations, to avoid emphasising inequalities between North and South (Asare et al., 2020). To this end, ensuring that clear ethics guidelines for conducting research are provided, research is designed in a participatory manner, and consideration is given to providing them in both the home language and in English.

\subsubsection{Micro Level}

The micro level relates to the immediate working environment of the researcher, and relates not just to their own attitudes, habits and skills, but those of the researchers with whom they collaborate. It is therefore important, particularly within IRC, that researchers are mindful of the cultural and linguistic differences that might exist and ensure that a culture of mutual respect and trust is fostered (Asare et al., 2020). This also extends to the choice of technology for communication within IRC, with the suggestion of an asynchronous space for collaboration, that allows collaborators take-up time, especially those for whom the collaborating language is not their first (Wöhlert, 2020). 
Researchers -especially early career researchers- are encouraged to use academic SNSs (e.g. ResearchGate) and social media (e.g. Twitter) to grow their professional learning network, which can raise the likelihood of establishing international collaborations (Gorska et al., 2020), and increase research and profile visibility internationally (Didegah, Gazni, Bowman, \& Holmberg, 2017).

\subsection{Limitations}

Whilst the study sheds light on IRC and provides perspectives to further explore, several limitations need to be acknowledged as well. The participants were recruited from English language, top educational journals, most of whom are located in the so-called academic centres, as opposed to the periphery (Altbach, 2016), and with high seniority levels, as opposed to being early career researchers. The criteria for selection of journals to select academics was based on their impact factor and not on their focus on "international research collaboration", which may bring an additional bias to the results.

With a focus on research in education science, this study's results are only limitedly applicable to other disciplines, due to potential field-specific motivations and circumstances. Furthermore, the use of a 10-point scale made conducting further statistical analyses and comparing data difficult, and therefore this would be revised in future iterations of this study to allow for more elaborate analysis and refined insights. It would also have been prudent to have separated the two questions in Round One, asking about the stages of research and technology used, which resulted in some participants not commenting on only one of these aspects.

A further relevant limitation is the number of experts that took part throughout the whole study, which went down drastically from the first round $(n=23)$ to the last one $(n$ $=14$ ) that could have driven the ratings and affected the reliability of the results obtained. We could also interpret that this reduction may be related to the format of the Delphi study (online). The Delphi study has, as an approach, the advantage of having individuals generate and revise their own perspective on a topic, without external influences of others. However, to discern opinions and perceptions somewhat more targeted, using qualitative interviews with individually selected participants and according to theoretical sampling would be, in retrospect, another means to approach the topic.

\section{CONCLUSIONS}

This study has contributed to further understanding of IRC in the context of educational research, a field where IRC has been less studied. The results indicate that established experts value developing and sharing new knowledge through IRC, rather than using it to build prestige. Further qualitative research (e.g. based on interviews) is therefore encouraged, to investigate a wider range of researchers' experiences and opinions of IRC, and should also extend to including publication outlets that are potentially more inclusive of geographically dispersed perspectives and different levels of academic seniority, to mitigate the structural limitations of the current study (leading and early-career researchers). 
Future research is also needed that explores institutional policies or plans to revise the value given to IRC in terms of regulations, particularly in light of the COVID-19 pandemic, and measures for promoting IRC among researchers.

\section{ADDITIONAL INFORMATION AND DECLARATIONS}

Data set: Bond, M., Marín, V. I., \& Bedenlier, S. (2021). International Collaboration in the Field of Educational Research: A Delphi Study. [Data set]. Zenodo. https://doi.org/10.528 1/zenodo.4534558

\section{REFERENCES}

Abramo, G., D’Angelo, C. A., \& Costa, F. D. (2019). The collaboration behavior of top scientists. Scientometrics, 118(1), 215-232. https://doi.org/10.1007/s11192-018-2970-9

Adams, J. (2013). The fourth age of research. Nature, 497, 557-560.

Aksnes, D. W., Frølich, N., \& Slipersæter, S. (2008). Science policy and the driving forces behind the internationalisation of science: the case of Norway. Science and Public Policy, 35(6), 445-457. https://doi.org/10.3152/030234208x331236

Aldieri, L., Kotsemir, M., \& Vinci, C. P. (2018). The impact of research collaboration on academic performance: An empirical analysis for some European countries. Socio-Economic Planning Sciences, 62, 13-30. https://doi.org/10.1016/j.seps.2017.05.003

Altbach, P. G. (2016). The university as center and periphery. Global perspectives on higher education (pp. 149-170). Johns Hopkins University Press.

Aman, V., \& Botte, A. (2017). A bibliometric view on the internationalization of European educational research. European Educational Research Journal, 16(6), 843-868. https://doi.org/ $10.1177 / 1474904117729903$

Asare, S., Mitchell, R., \& Rose, P. (2020). How equitable are South-North partnerships in education research? Evidence from sub-Saharan Africa. Compare: A Journal of Comparative and International Education, 1-20. Retrieved from https://dx.doi.org/10.1080/03057925.2020.1811638 $10.1080 / 03057925.2020 .1811638$

Baker, S. (2020, August 3). How Covid-19 is reshaping international research collaboration. Retrieved from https://www.timeshighereducation.com/news/how-covid-19-reshaping -international-research-collaboration

Bardakcı, S., Arslan, Ö., \& Ünver, T. K. (2018). How scholars use academic social networking services. Information Development, 34(4), 334-345. https://doi.org/10.1177/0266666917712108

Berthoud, L., \& Gliddon, J. (2018). Using wikis to investigate communication, collaboration and engagement in Capstone engineering design projects. European Journal of Engineering Education, 43(2), 247-263. https://doi.org/10.1080/03043797.2017.1332574

Bogle, D. (2020). How will COVID-19 affect research collaboration? Retrieved from https://www .universityworldnews.com/post.php?story $=2020090413393595$

Bond, M., \& Bedenlier, S. (2019). Facilitating Student Engagement Through Educational Technology: Towards a Conceptual Framework. Journal of Interactive Media in Education, 2019(1), 1-14. Retrieved from https://dx.doi.org/10.5334/jime.528 10.5334/jime.528

Bond, M., \& Buntins, K. (2018). An analysis of the Australasian Journal of Educational Technology 2013-2017. Australasian Journal of Educational Technology, 34(4), 168-183. https://doi.org/ 10.14742/ajet.4359 
Bond, M., Zawacki-Richter, O., \& Nichols, M. (2019). Revisiting five decades of educational technology research: A content and authorship analysis of the British Journal of Educational Technology. British Journal of Educational Technology, 50(1), 12-63. https://doi.org/10.111/ bjet.12730

Bote, V. P. G., Olmeda-Gómez, C., \& de Moya-Anegón, F. (2013). Quantifying the benefits of international scientific collaboration. Journal of the American Society for Information Science and Technology, 64(2), 392-404. https://doi.org/10.1002/asi.22754

Bothwell, E. (2019, September 11). THE World University Rankings 2020: Productivity gains. Retrieved from https://www.timeshighereducation.com/world-university-rankings/ world-university-rankings-2020-productivity-gains

Bozeman, B., Gaughan, M., Youtie, J., Slade, C. P., \& Rimes, H. (2016). Research collaboration experiences, good and bad: Dispatches from the front lines. Science and Public Policy, 43(2), 226-244. https://doi.org/10.1093/scipol/scv035

Bu, Y., Ding, Y., Liang, X., \& Murray, D. S. (2018). Understanding persistent scientific collaboration. Journal of the Association for Information Science and Technology, 69(3), 438-448. https:// doi.org/10.1002/asi.23966

Buckner, E. (2020). Embracing the global: the role of ranking, research mandate, and sector in the internationalisation of higher education. Compare: A Journal of Comparative and International Education, 1-18. https://doi.org/10.1080/03057925.2020.1753499

Buitendijk, S., Ward, H., Shimshon, G., Sam, A. H., Sharma, D., \& Harris, M. (2020). COVID-19: an opportunity to rethink global cooperation in higher education and research. BMJ Global Health, 5(7), e002790-e002790. https://doi.org/10.1136/bmjgh-2020-002790

Bukvova, H. (2010). Studying research collaboration: A literature review. Sprouts: Working Papers on Information Systems, 10(3), 1-17.

Caniglia, G., Luederitz, C., Groß, M., Muhr, M., John, B., Keeler, L. W., ... Lang, D. (2017). Transnational collaboration for sustainability in higher education: Lessons from a systematic review. Journal of Cleaner Production, 168, 764-779. https://doi.org/10.1016/j.jclepro.2017.07.256

Chen, K., Zhang, Y., \& Fu, X. (2019). International research collaboration: An emerging domain of innovation studies? Research Policy, 48, 149-168. https://doi.org/10.1016/j.respol.2018.08 .005

Defazio, D., Lockett, A., \& Wright, M. (2009). Funding incentives, collaborative dynamics and scientific productivity: Evidence from the EU framework program. Research Policy, 38(2), 293-305. https://doi.org/10.1016/j.respol.2008.11.008

DeHart, D. (2017). Team science: A qualitative study of benefits, challenges, and lessons learned. The Social Science Journal, 54(4), 458-467. https://doi.org/10.1016/j.soscij.2017.07.009

Didegah, F., Gazni, A., Bowman, T. D., \& Holmberg, K. (2017). Internationality in Finnish research: An examination of collaborators, citers, tweeters, and readers. Information Research-an International Electronic Journal, 22(1), 22-22. Retrieved from http://www.informationr.net/ir/ 22-1/colis/colis1624.html

Englander, K., \& Uzuner-Smith, S. (2013). The role of policy in constructing the peripheral scientist in the era of globalization. Language Policy, 12(3), 231-250. https://doi.org/10.1007/s10993 -012-9268-1

Fake, H. (2018). A Delphi Study on the Dimensions of Personalized Learning in Workforce Training and Development Programs (Unpublished doctoral dissertation). George Mason University.

Fernández, A., Ferrándiz, E., \& León, M. D. (2016). Proximity dimensions and scientific collaboration among academic institutions in Europe: The closer, the better? Scientometrics, 106(3), 1073-1092. https://doi.org/10.1007/s11192-015-1819-8

Fry, C. V., Cai, X., Zhang, Y., \& Wagner, C. S. (2020). Consolidation in a crisis: Patterns of inter- 
national collaboration in early COVID-19 research. PLOS ONE, 15(7), e0236307-e0236307. htthttps://doi.org/10.1371/journal.pone.0236307

Fu, J. Y., Zhang, X., Zhao, Y. H., Tong, H. F., Chen, D. Z., \& Huang, M. H. (2012). Scientific production and citation impact: a bibliometric analysis in acupuncture over three decades. Scientometrics, 93(3), 1061-1079. https://doi.org/10.1007/s11192-012-0737-2

Gazni, A., Sugimoto, C. R., \& Didegah, F. (2012). Mapping world scientific collaboration: Authors, institutions, and countries. Journal of the American Society for Information Science and Technology, 63(2), 323-335. https://doi.org/10.1002/asi.21688

Gorska, A., Korzynski, P., Mazurek, G., \& Pucciarelli, F. (2020). The Role of Social Media in Scholarly Collaboration: An Enabler of International Research Team's Activation? Journal of Global Information Technology Management, 23(4), 273-291. https://doi.org/10.1080/1097198x.2020 .1817684

Guo, S., Zhang, G., \& Guo, Y. (2016). Social network analysis of 50 years of international collaboration in the research of educational technology. Journal of Educational Computing Research, 53(4), 499-518. https://doi.org/10.1177/0735633115611114

Hall, K. L., Vogel, A. L., Huang, G. C., Serrano, K. J., Rice, E. L., Tsakraklides, S. P., \& Fiore, S. M. (2018). The science of team science: A review of the empirical evidence and research gaps on collaboration in science. American Psychologist, 73(4), 532-548. https://doi.org/10.1037/ amp0000319

Henriksen, D. (2016). The rise in co-authorship in the social sciences. Scientometrics, 107(2), 455-476. https://doi.org/10.1007/s11192-016-1849-x

Henriksen, D. (2018). What factors are associated with increasing co-authorship in the social sciences? A case study of Danish Economics and Political Science. Scientometrics, 114(3), 13951421. https://doi.org/10.1007/s11192-017-2635-0

Hoffman, D. M., Blasi, B., Ćulum, B., Žarko Dragšić, Ewen, A., Horta, H., .. Rios-Aguilar, C. (2014). The methodological illumination of a blind spot: information and communication technology and international research team dynamics in a higher education research program. Higher Education, 67(4), 473-495. https://doi.org/10.1007/s10734-013-9692-y

Hook, D., \& Porter, S. (2020). How COVID-19 is Changing Research Culture. https://doi.org/10.6084/ m9.figshare.12383267.v2

Horgan, D., Hackett, J., Westphalen, C. B., Kalra, D., Richer, E., Romao, M., .. Montserrat, A. (2020). Digitalisation and COVID-19: The Perfect Storm. Biomedicine Hub, 5(3), 1-23. https://doi .org/10.1159/000511232

Hsu, C. C., \& Sandford, B. (2007). The delphi technique: Making sense of consensus. Research \& Evaluation, 12(10), 1-8. https://doi.org/10.7275/pdz9-th90

Iglič, H., Doreian, P., Kronegger, L., \& Ferligoj, A. (2017). With whom do researchers collaborate and why? Scientometrics, 112(1), 153-174. https://doi.org/10.1007/s11192-017-2386-y

International Telecommunication Union. (2020, July). Economic impact of COVID-19 on digital infrastructure: Report of an Economic Experts Roundtable organized by ITU (GSR-20 Discussion Paper). Retrieved from https://www.itu.int/en/ITU-D/Conferences/GSR/2020/ Documents/GSR-20_Impact-COVID-19-on-digital-economy_DiscussionPaper.pdf

John, A., Eyles, E., Mcguinness, L. A., Okolie, C., Olorisade, B. K., Schmidt, L., \& Higgins, J. P. (2020). The impact of the COVID-19 pandemic on self-harm and suicidal behaviour: protocol for a living systematic review. The impact of the COVID-19 pandemic on self-harm and suicidal behaviour: protocol for a living systematic review, 9. https://doi.org/10.12688/f1000research .24274 .1

Jonsen, K., Butler, C. L., Mäkelä, K., Piekkari, R., Drogendijk, R., Lauring, J., ... Zander, L. (2013). Processes of International Collaboration in Management Research. Journal of Management 
Inquiry, 22(4), 394-413. https://doi.org/10.1177/1056492612464429

Kahn, M. (2018). Co-authorship as a proxy for collaboration: a cautionary tale. Science and Public Policy, 45(1), 117-123. https://doi.org/10.1093/scipol/scx052

Kato, M., \& Ando, A. (2013). The relationship between research performance and international collaboration in chemistry. Scientometrics, 97(3), 535-553. https://doi.org/10.1007/s11192 -013-1011-y

Katz, J. S., \& Martin, B. R. (1997). What is research collaboration? Research Policy, 26, 917-918. https://doi.org/10.1016/S0048-7333(96

Khor, K. A., \& Yu, L. G. (2016). Influence of international co-authorship on the research citation impact of young universities. Scientometrics, 107(3), 1095-1110. https://doi.org/10.1007/ s11192-016-1905-6

King, K. (1985). North-South Collaborative Research in Education. International Journal of Educational Development, 5(3), 183-191.

Ku, M., Gil-Garcia, J. R., \& Zhang, J. (2016). The emergence and evolution of cross-boundary research collaborations: An explanatory study of social dynamics in a digital government working group. Government Information Quarterly, 33(4), 796-806. https://doi.org/10.1016/ j.giq.2016.07.005

Kuld, L., \& O’Hagan, J. (2018). Rise of multi-authored papers in economics: Demise of the 'lone star' and why? Scientometrics, 114(3), 1207-1225. https://doi.org/10.1007/s11192-017-2588-3

Kumar, S. (2018). Ethical concerns in the rise of co-authorship and its role as a proxy of research collaborations. Publications, 6(3), 1-9. https://doi.org/10.3390/publications6030037

Kumar, S., \& Ratnavelu, K. (2016). Perceptions of Scholars in the Field of Economics on Co-Authorship Associations: Evidence from an International Survey. PLOS ONE, 11(6), e0157633-e0157633. https://doi.org/10.1371/journal.pone.0157633

Kwiek, M. (2018). International research collaboration and international research orientation: Comparative findings about European academics. Journal of Studies in International Education, 22(2), 136-160. https://doi.org/10.1177/1028315317747084

Kwiek, M. (2019a). Internationalisation of EU research organisations: A bibliometric stocktaking study. https://doi.org/10.2861/68729

Kwiek, M. (2019b). Social stratification in higher education: What it means at the micro-level of the individual academic scientist. Higher Education Quarterly, 81(1), 1-26. https://doi.org/ 10.1111/hequ.12221

Kwiek, M. (2020a). Internationalists and locals: international research collaboration in a resourcepoor system. Scientometrics, 124(1), 57-105. https://doi.org/10.1007/s11192-020-03460-2

Kwiek, M. (2020b). What Large-Scale Publication and Citation Data Tell Us About International Research Collaboration in Europe: Changing national patterns in global contexts. Studies in Higher Education, 45(4), 1-24. https://doi.org/10.1080/03075079.2020.1749254

Leahey, E. (2016). From Sole Investigator to Team Scientist: Trends in the Practice and Study of Research Collaboration. Annual Review of Sociology, 42(1), 81-100. https://doi.org/10.1146/ annurev-soc-081715-074219

Lee, J. J., \& Haupt, J. P. (2020a). International Research Collaborations on COVID-19 Amidst Geopolitical Tensions with China. , 1-11. https://doi.org/10.21203/rs.3.rs-37599/v1

Lee, J. J., \& Haupt, J. P. (2020b). Scientific globalism during a global crisis: Research collaboration and open access publications on COVID-19. Higher Education, 81, 949-966. https://doi.org/ 10.1007/s10734-020-00589-0

Linstone, H. A., \& Turoff, M. (2002). The Delphi Method: Techniques and Applications. Retrieved from https://www.researchgate.net/file.PostFileLoader.html?id= 563b341d5cd9e375988b45bc\&assetKey=AS\%3A292381292285964\%401446720541026 
Macfarlane, B. (2017). The paradox of collaboration: a moral continuum. Higher Education Research \& Development, 36(3), 472-485. https://doi.org/10.1080/07294360.2017.1288707

Mali, F., Pustovrh, T., Cugmas, M., \& Ferligoj, A. (2018). The personal factors in scientific collaboration: views held by Slovenian researchers. Corvinus Journal of Sociology and Social Policy, 9(2), 3-24. https://doi.org/10.14267/cjssp.2018.2.01

Marín, V. I., \& Zawacki-Richter, O. (2019). Scientific Communication between Spanish and English Educational Technology Journals. A Citation Analysis of eight Journals. Journal of New Approaches in Educational Research, 8(2), 96-96. https://doi.org/10.7821/naer.2019.7.393

Mason, S. (2020). Adoption and usage of Academic Social Networks: a Japan case study. Scientometrics, 6(1), 1-17. https://doi.org/10.1007/s11192-020-03345-4

Matthews, K. R. W., Yang, E., Lewis, S. W., Vaidyanathan, B. R., \& Gorman, M. (2020). International scientific collaborative activities and barriers to them in eight societies. Accountability in Research, 27(8), 477-495. https://doi.org/10.1080/08989621.2020.1774373

Melin, G. (2000). Pragmatism and self-organization. Research Policy, 29(1), 31-40. https://doi.org/ 10.1016/s0048-7333(99)00031-1

Muriithi, P., Horner, D., \& Pemberton, L. (2016). Factors contributing to adoption and use of information and communication technologies within research collaborations in Kenya. Information Technology for Development, 22, 84-100. https://doi.org/10.1080/02681102.2015 .1121856

Muriithi, P., Horner, D., Pemberton, L., \& Wao, H. (2018). Factors influencing research collaborations in Kenyan universities. Research Policy, 47(1), 88-97. https://doi.org/10.1016/ j.respol.2017.10.002

National Science Foundation. (2020). Dear Colleague Letter: Future of International Research Collaboration Post COVID-19. Retrieved from https://www.nsf.gov/pubs/2020/nsf20132/ nsf20132.jsp

Niederkrotenthaler, T., Gunnell, D., Arensman, E., Pirkis, J., Appleby, L., Hawton, K., ... Platt, S. (2020). Suicide Research, Prevention, and COVID-19. Crisis, 41(5), 321-330. https://doi.org/ 10.1027/0227-5910/a000731

Okoli, C., \& Pawlowski, S. D. (2004). The Delphi method as a research tool: an example, design considerations and applications. Information \& Management, 42(1), 15-29. https://doi.org/ 10.1016/j.im.2003.11.002

O’Neill, S., Scott, M., \& Conboy, K. (2011). A Delphi study on collaborative learning in distance education: The faculty perspective. British Journal of Educational Technology, 42(6), 939-949. https://doi.org/10.1111/j.1467-8535.2010.01132.x

Payumo, J., Sutton, T., Brown, D., Nordquist, D., Evans, M., Moore, D., \& Arasu, P. (2017). Inputoutput analysis of international research collaborations: a case study of five U.S. universities. Scientometrics, 111(3), 1657-1671. https://doi.org/10.1007/s11192-017-2313-2

Ponomariov, B., \& Boardman, C. (2016). What is co-authorship? Scientometrics, 109(3), 1939-1963. https://doi.org/10.1007/s11192-016-2127-7

Queen's University Belfast. (2020). Why a collaborative research culture is needed to address the COVID-19 challenge. Retrieved from https:/www.qub.ac.uk/coronavirus/analysis -commentary/collaborative-research-culture-needed-to-address-covid-19/

Remedios, L., \& Gummesson, C. (2018). Learning with and from each other: promoting international and interprofessional collaborations in physiotherapy education research - a literature review. Physical Therapy Reviews, 23(1), 4-10. https://doi.org/10.1080/10833196.2018 .1449792

Salinas, J., \& Marín, V. I. (2019). Metasíntesis cualitativa sobre colaboración científica e identidad digital académica en redes sociales. RIED. Revista Iberoamericana De Educación a Distancia, 


\section{2. https://doi.org/10.5944/ried.22.2.23238}

Sonnenwald, D. H. (2007). Scientific collaboration. Annual Review of Information Science and Technology, 41(1), 643-681. https://doi.org/10.1002/aris.2007.1440410121

Sooryamoorthy, R., \& Shrum, W. (2007). Does the Internet Promote Collaboration and Productivity? Evidence from the Scientific Community in South Africa. Journal of Computer-Mediated Communication, 12(2), 733-751. https://doi.org/10.1111/j.1083-6101.2007.00347.x

Stevis, G. M., \& Jakes, L. (2020). World Leaders Join to Pledge \$8 Billion for Vaccine as U.S. Goes It Alone. New York Times. Retrieved from https://www.nytimes.com/2020/05/04/world/ europe/eu-coronavirus-vaccine.html

Stokols, D., Misra, S., Moser, R. P., Hall, K. L., \& Taylor, B. K. (2008). The ecology of team science: Understanding contextual influences on transdisciplinary collaboration. American Journal of Preventive Medicine, 35(2), 96-115. https://doi.org/10.1016/j.amepre.2008.05.003

Tight, M. (2018). Higher education journals: their characteristics and contribution. Higher Education Research \& Development, 37(3), 607-619. https://doi.org/10.1080/07294360.2017 .1389858

Times Higher Education. (2019). THE World University Rankings 2020: methodology. Retrieved from https://www.timeshighereducation.com/world-university-rankings/ methodology-world-university-rankings-2020

Waltman, L., Tijssen, R. J., \& van Eck, N. J. (2011). Globalisation of science in kilometres. Journal of Informetrics, 5(4), 574-582. https://doi.org/10.1016/j.joi.2011.05.003

Wang, W., Yu, S., Bekele, T. M., Kong, X., \& Xia, F. (2017). Scientific collaboration patterns vary with scholars' academic ages. Scientometrics, 112(1), 329-343. Retrieved from https:/dx.doi.org/ 10.1007/s11192-017-2388-9 10.1007/s11192-017-2388-9

Wöhlert, R. (2020). Communication in international collaborative research teams. A review of the state of the art and open research questions. Studies in Communication and Media, 9(2), 151-217. https://doi.org/10.5771/2192-4007-2020-2-151

Yemini, M. (2019). International Research Collaborations as Perceived by Top-Performing Scholars. Journal of Studies in International Education, 25(1), 3-18. https://doi.org/10.1177/ 1028315319887392

Ynalvez, M. A., \& Shrum, W. M. (2011). Professional networks, scientific collaboration, and publication productivity in resource-constrained research institutions in a developing country. Research Policy, 40(2), 204-216. https://doi.org/10.1016/j.respol.2010.10.004

Yousuf, M. I. (2007). Using experts' opinions through delphi technique. Research \& Evaluation, 12(4), 1-8. https://doi.org/10.7275/rrph-t210

Zhou, P., \& Tian, H. (2014). Funded collaboration research in mathematics in China. Scientometrics, 99(3), 695-715. https://doi.org/10.1007/s11192-013-1212-4 